\title{
RANCANG BANGUN SISTEM APLIKASI AKADEMIK YAYASAN PENDIDIKAN ISLAM DAARURRAHMAH BOGOR BERBASIS DESKTOP
}

\author{
Cendani Khoirun Nissa \\ Program Studi Informatika, Fakultas Teknik dan Ilmu Komputer, Universitas Indraprasta PGRI \\ Jalan Raya Tengah No 80, Kelurahan Gedong, Pasar Rebo, Jakarta Timur \\ cendaninissa@gmail.com
}

\begin{abstract}
Abstrak
Yayasan Pendidikan Islam Daarurrahmah (YAPIDA) ini termasuk sekolah yang jumlah siswanya tiap tahun meningkat dilihat dari tahun-tahun sebelumnya, hal ini menyebabkan kepala sekolah tidak dapat mengelola semuanya dengan baik dan merasa kerepotan menangani hal tersebut. Dikarenakan proses pendataan yang masih manual, sehingga dirasa kurang optimal dan memerlukan proses yang cukup lama baik dalam menyusun laporan. Dengan demikian masalah yang akan diselesaikan adalah bagaimana membangun sistem informasi akademik yang dapat mempermudah dalam mencari data dan mempermudah dalam penyusunan laporan secara terstruktur.Tujuan penelitian adalah menghasilkan rancangan aplikasi sistem akademik sekolah berbasis desktop untuk memberikan manfaat melalui aplikasi tersebut serta menghasilkan aplikasi yang informatif dan interaktif sehingga memudahkan pengguna dalam pencarian basis data. Metodologi yang digunakan oleh peneliti adalah studi pustaka meliputi pencarian sumber informasi yang mendukung serta memadai dalam penelitian ini, dan studi lapangan meliputi survei tempat peneliti, wawancara, serta melihat dokumentasi untuk menambah informasi yang akan diteliti.
\end{abstract}

Kata Kunci: Informasi Akademik, Basis Data, Aplikasi Desktop.

\begin{abstract}
The Daarurrahmah Islamic Education Foundation (YAPIDA) includes schools whose number of students each year increases in views from previous years, causing the headmaster not to manage everything well and feel the hassles of handling it. Because the logging process is still manual, so it felt less optimal and requires a long enough process either to compile the report. Thus the problem to be solved is how to build an academic information system that can facilitate the searching of data and make it easier in structured report preparation. The purpose of the research is to produce the design of a desktop-based school academic system application to provide benefits through the application and generate informative and interactive applications that facilitate users in search Database. The methodology used by researchers is the study of libraries including the search for a supportive and adequate source of information in this study, and field studies include surveys of researchers, interviews, and documentation to add to Information to be researched.
\end{abstract}

Keywords: Academic Information, Database, Desktop Applications.

\section{PENDAHULUAN}

Yayasan Pendidikan Islam Daarurrahmah (YAPIDA) merupakan sekolah yang jumlah siswanya tiap tahun meningkat dilihat dari tahun-tahun sebelumnya, hal ini menyebabkan kepala sekolah tidak dapat mengelola semuanya dengan baik dan merasa kerepotan menangani hal tersebut. Dikarenakan proses pendataan yang masih manual, sehingga dirasa kurang optimal dan memerlukan proses yang cukup lama baik dalam menyusun laporan. Dengan demikian masalah yang akan diselesaikan adalah bagaimana membangun sistem informasi akademik yang dapat mempermudah dalam mencari data dan mempermudah dalam penyusunan laporan secara terstruktur. Sistem adalah kumpulan atau himpunan dari unsur, kompenen, atau variabel yang terorganisasi, saling berinteraksi, saling tergantung satu sama lain dan terpadu(Sutabri, 2012). Informasi adalah data yang diolah menjadi bentuk yang lebih berguna dan lebih berarti bagi yang menerimanya, sedangkan data merupakan sumber informasi yang menggambarkan suatu kejadian yang nyata (Mulyanto, 2009). Informasi merupakan data yang telah diorganisasi dan telah memiliki kegunaan dan manfaat (Krismaji, 2015). Perancangan sistem adalah sekumpulan aktivitas yang menggambarkan secara rinci bagaimana sistem akan berjalan. Hal itu bertujuan untuk menghasilkan produk perangkat lunak yang sesuai dengan kebutuhan user(Satzinger et al., 2012). 
Tujuan penelitian ini adalah menghasilkan rancangan aplikasi sistem akademik sekolah berbasis desktop untuk memberikan manfaat melalui aplikasi tersebut serta menghasilkan aplikasi yang informatif dan interaktif sehingga memudahkan pengguna dalam pencarian basis data. Aplikasi adalah adalah software yang dibuat oleh suatu perusahaan komputer untuk mengerjakan tugastugas tertentu, misalnya Microsoft Word, Microsoft Excel (Dhanta, 2015).

Manfaat dari penelitian ini adalah Yayasan Pendidikan Islam Daarurrahmah diharapkan dapat menerapkan sistem yang baru sehingga menghasilkan data atau informasi dengan lebih efektif dan efisien. Serta dapat memudahkan siswa dalam mendapatkan informasi data-data akademik sekolah secara umum. Juga dapat berguna bagi pihak-pihak yang memerlukan baik sebagai referensi, bahan pembanding, maupun sebagai bahan rujukan untuk mengadakan penelitian lebih lanjut.

\section{PENELITIAN RELEVAN}

Dalam melakukan penelitian tentang sistem informasi akademik berbasis web, penulis menggunakan bahan referensi dari berbagai sumber, antara lain dari jurnal yang relevan dengan penelitian yang peneliti lakukan. Penelitian oleh Melan Susanti dengan judul Perancangan Sistem Informasi Akademik Berbasis Web Pada Smk Pasar Minggu Jakarta. Hasil Penelitian adalah Perancangan sistem informasi akademik berbasis web dapat memberikan pelayanan optimal kepada siswa dan orang tua sehingga tidak perlu datang ke sekolah untuk mendapatkan informasi akademik, sehingga dihasilkan informasi yang cepat dan akurat. (Susanti, 2016)

\section{METODE PENELITIAN}

Peneliti menggunakan metode penelitian Grounded Research dalam pelaksanaan penelitian ini. Metode Grounded Research adalah reaksi terhadap metode penelitian yang asasnya verifikasi teori. Dalam grounded research data merupakan sumber teori dan teori disebut grounded karena teori tersebut berdasarkan fakta.

Teknik pengumpulan data selama penelitian berupa survey tempat, wawancara kepada pihak yang bertanggungjawab dalam mengelola akademik sekolah, melakukan observasi dengan cara pengumpulan data dengan mengadakan pengamatan langsung terhadap suatu objek dalam suatu periode tertentu dan mengadakan pencatatan secara sistematis tentang hal-hal tertentu yang diamati. Peneliti mempelajari dan mengamati sistem informasi akademik siswa yang terdapat di SMA Yapida.

Desain Penitilian melalui tahap perancangan struktur data, arsitektur perangkat lunak, rincian procedural, karakteristik antar muka dan dirancanng tampilan layar seperti form masukan dan form keluaran dari sistem yang akan dirancang.

Kemudian ditahap menganalisa kebutuhan sistem dilakukan pengumpulan kebutuhan dengan fokus pada perangkat lunak, meliputi informasi, fungsi masing-masing bagian sistem, kerja atau cara kerja antar muka. Lalu menyediakan perangkat dan teknik yang dapat membantu peneliti untuk menentukan kebutuhan melalui sistem yang telah berjalan pada sistem informasi akademik terutama dalam pengolahan data-datanya. Perangkat yang dimaksud adalah penggunaan Diagram Alir data(DAD) untuk menyusun data masukan (input), proses (process), da keluaran (output).

\section{HASIL DAN PEMBAHASAN}

Diagram Konteks Diusulkan

Diagram ini akan mengurai proses sistem yang akan diusulkan, sebagai berikut: 


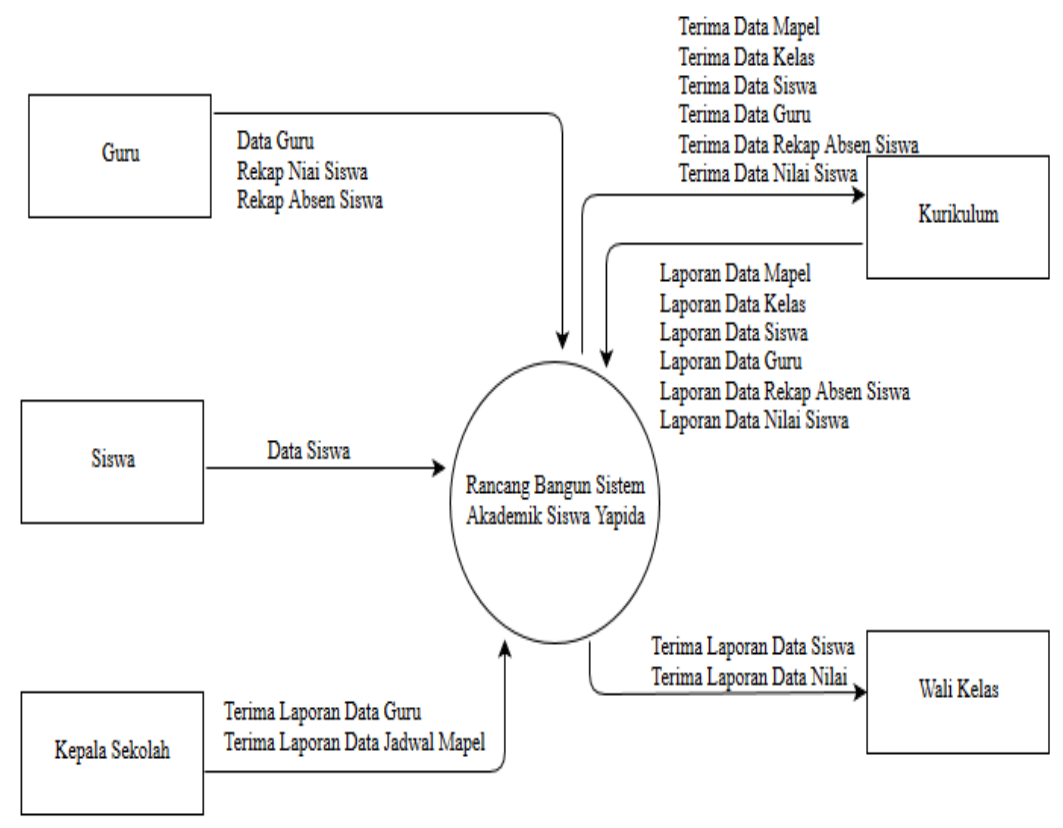

Gambar 1. Diagram Konteks yang Diusulkan

Dari penjelasan diagram konteks diatas bahwa di dalam rancang bangun sistem akademik bagian kurikulum lebih berkompeten dalam mengatur data-data yang ada di sekolah.

\section{Diagram Nol Diusulkan}

Diagram ini akan mengurai proses sistem yang akan diusulkan, sebagai berikut:

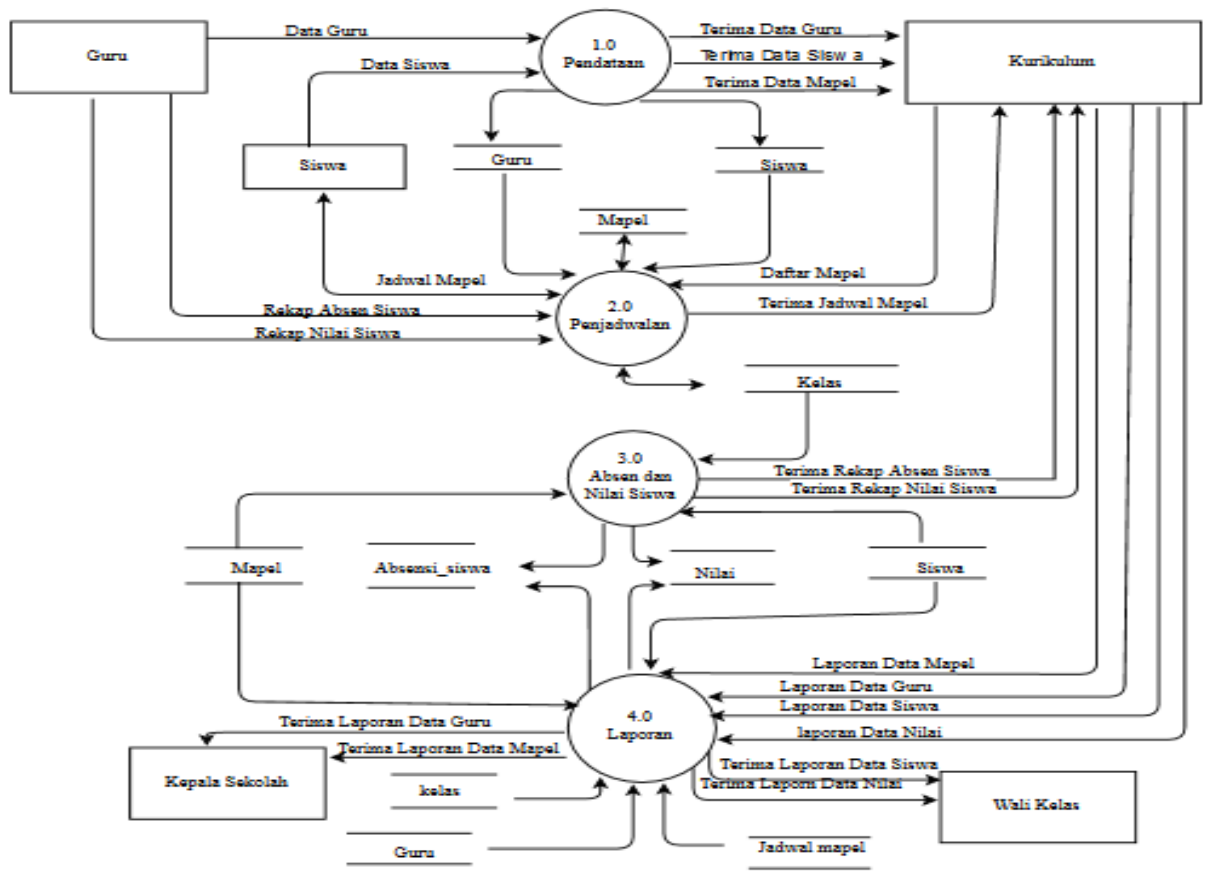

Gambar 2. Diagram Nol Diusulkan

Dari diagram nol diatas semua bagian terlibat kerjasama dalam mendata seluruh aspek didalam bagiannya masing-masing sehingga semua data diterima oleh kurikulum dan dibentuk dalam data yang terstruktur serta memudahkan dalam pelaporan data akhir kepada kepala sekolah. 


\section{Diagram Rinci 1.1 Diusulkan}

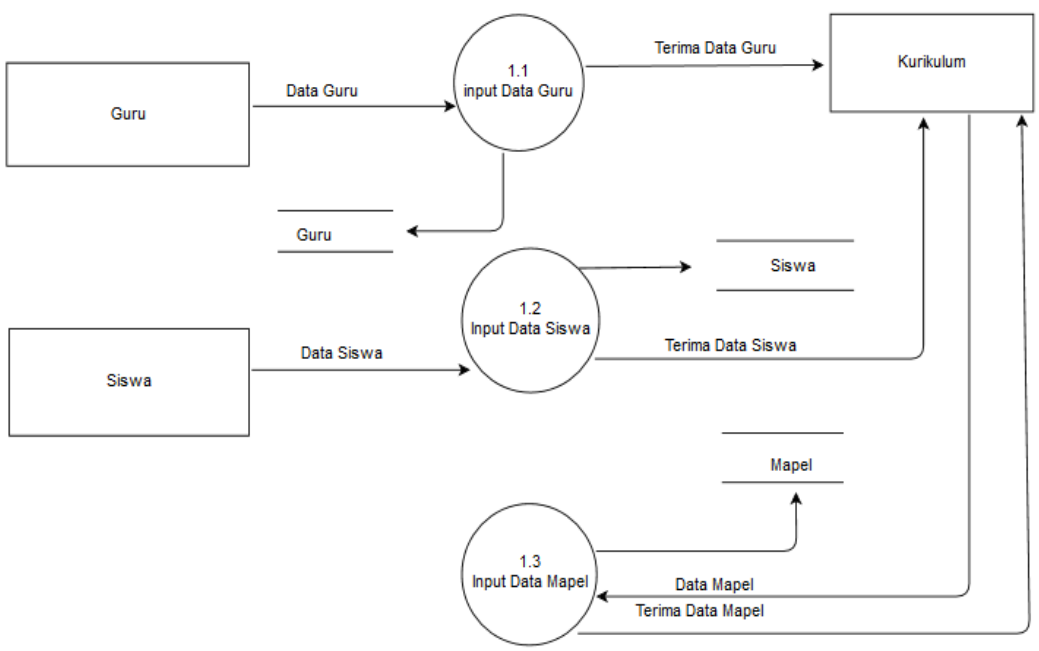

Gambar 3. Diagram Rinci 1.1 Diusulkan

Dari Diagram Rinci seluruh data yang berkaitan dengan pengajar dan siswa disimpan dalam sebuah database untuk memudahkan kinerja staf dalam mencari data.

\section{Entity Relationship Diagram (ERD)}

Berikut gambar diagram Entity Relationship Diagram (ERD) yang akan diusulkan pada Yayasan Pendidikan Islam Daarurrahmah, sebagai berikut:

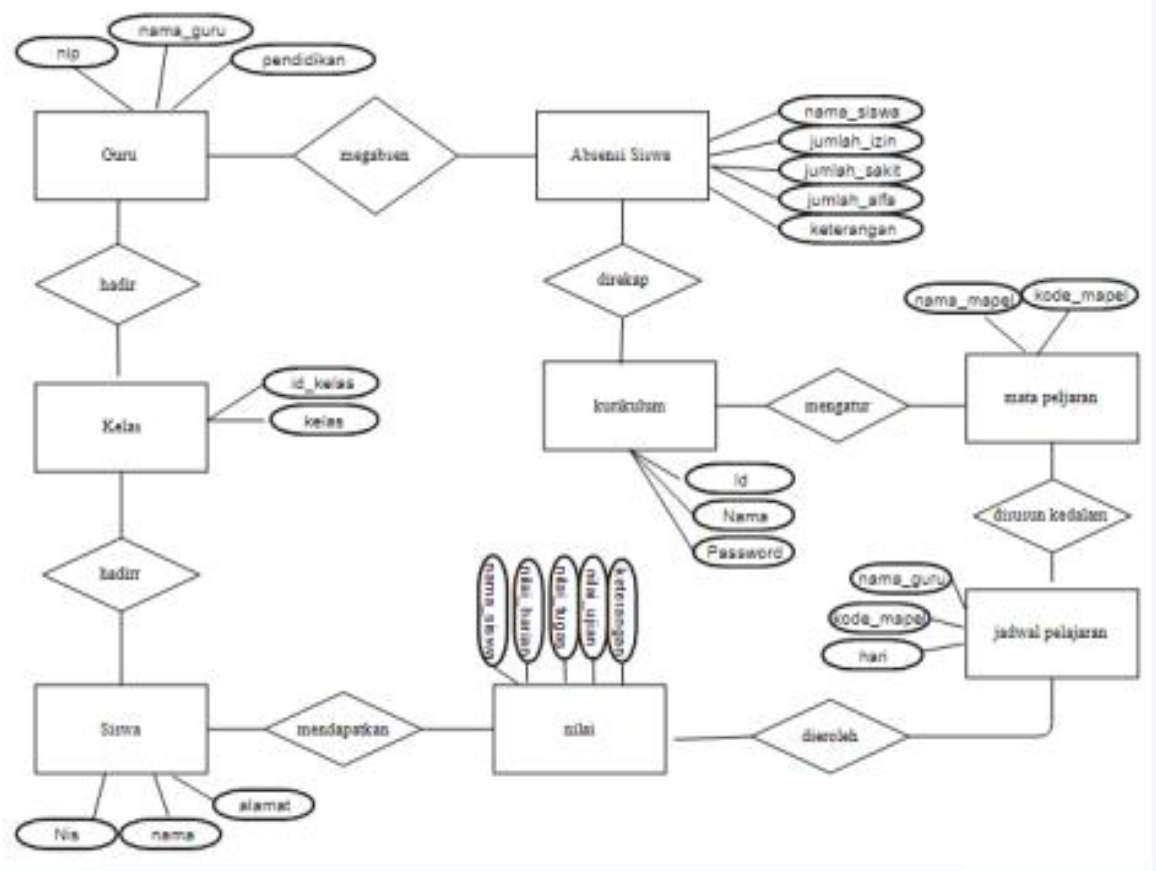

Gambar 4. Entity Relationship Diagram (ERD)

Diagram ERD membentuk sebuah rancangan data pada layar aplikasi yang akan dibuat, masingmasing nama data mempunyai sebuah database didalamnya agar memudahkan dalam mengisi dan mengubah data jika diperlukan. 


\section{Perancangan dan Tampilan Layar Aplikasi Sistem Akademik}

Rancangan layar merupakan rancangan bangun percakapan antara pengguna dengan komputer yang terdiri dari proses memasukan data ke sistem kemudian menampilkan kembali keluaran informasi kepada pengguna dengan uraian sebagai berikut:

\section{Form Login}

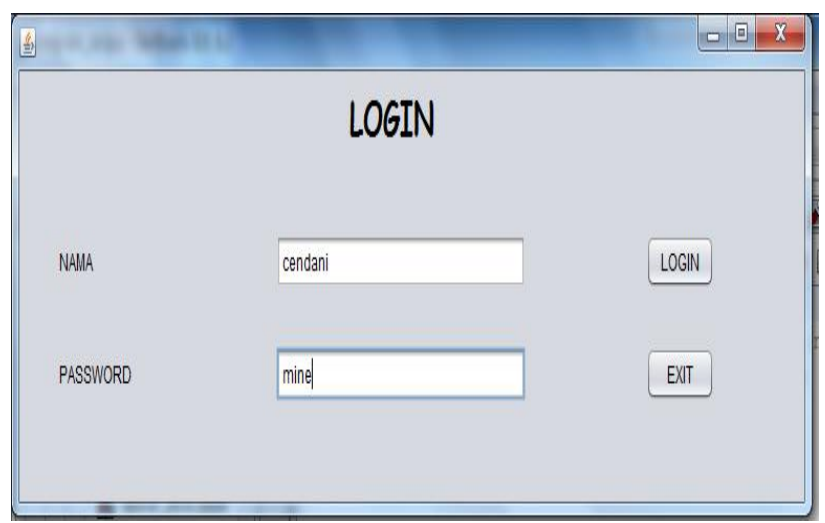

Gambar 5. Form Login

Form login diisi saat ingin menggunakan data aplikasi agar sistem penyimpanan data terjaga dengan rapih.

\section{Form Menu Utama}

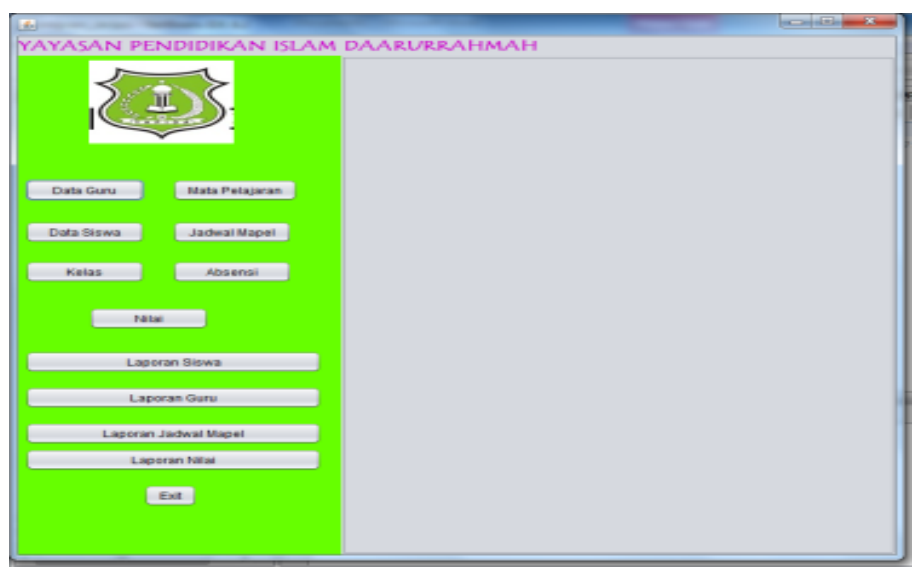

Gambar 6. Form Menu Utama

Form Menu Utama merupakan tampilan awal pada layar aplikasi dan dibuat secara berurutan agar data yang sudah disimpan sesuai dengan kategori datanya masing-masing.

\section{Form Data Siswa}

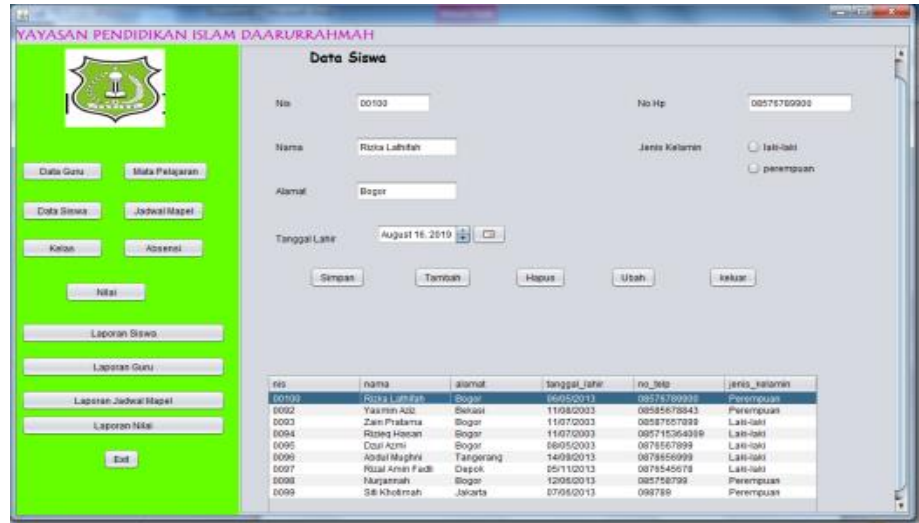

Gambar 7. Form Data Siswa 
Form Data siswa diisi sesuai dengan identitas siswa yang mana data tersebut untuk memudahkan bagian kurikulum dalam mencari data siswa jika sewaktu diperlukan.

\section{Form Data Guru}

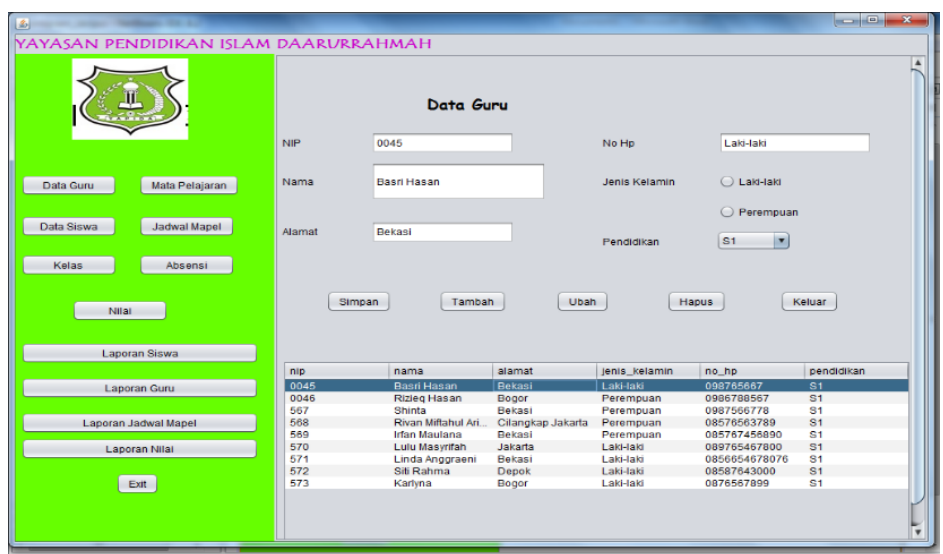

Gambar 8. Form Data Guru

Form Data guru diisi sesuai dengan identitas guru yang mana data tersebut akan digunakan untuk pendataan jadwal mengajar, profil guru, serta data honorarium guru.

\section{Form Laporan Data Guru}

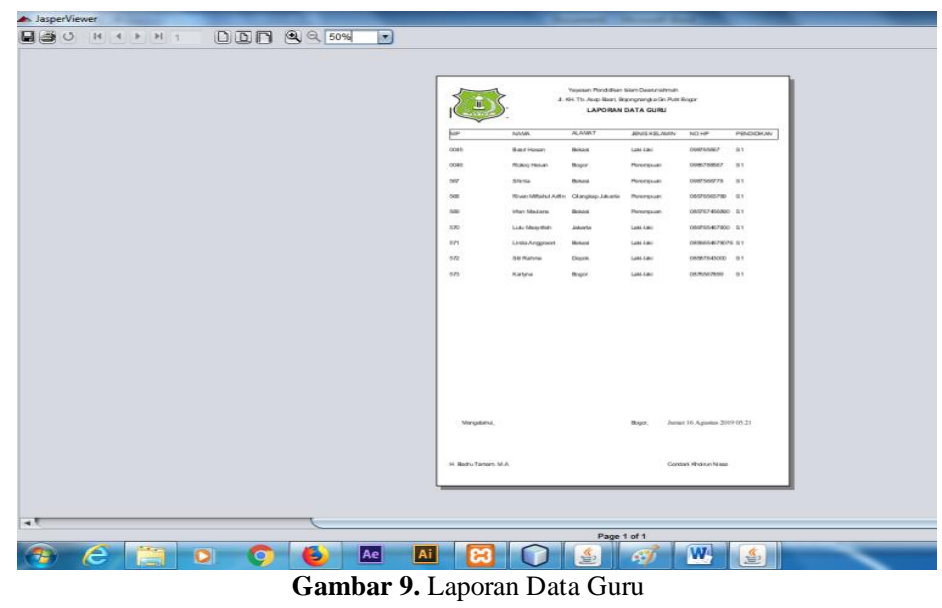

Laporan data guru merupakan hasil pendataan akhir yang akan dilaporkan setiap bulannya kepada kepala sekolah untuk meninjau identitas dan jumlah guru yang mengajar di yapida.

\section{Form Laporan Data Siswa}

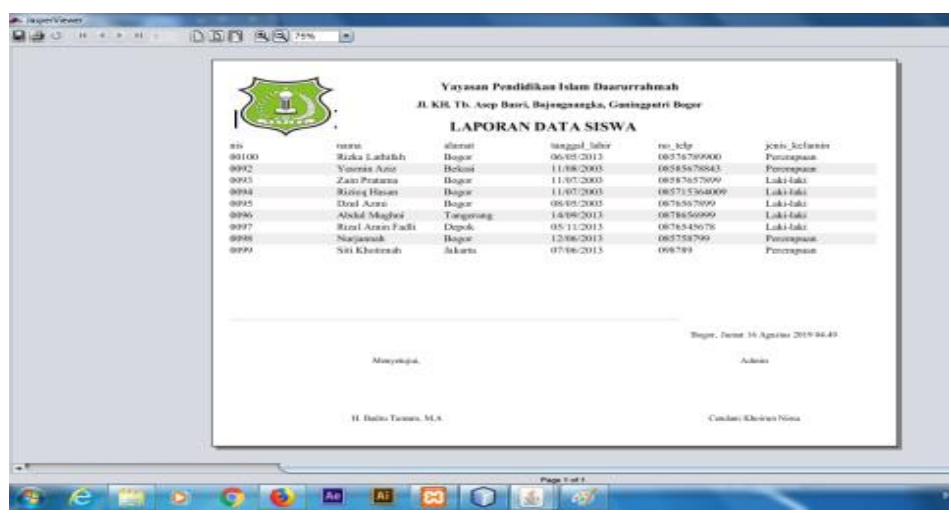

Gambar 10. Laporan Data Siswa 
Laporan data siswa merupakan hasil pendataan akhir yang akan dilaporkan setiap bulannya kepada kepala sekolah untuk meninjau jumlah siswa yang ada maupun siswa yang pindah.

\section{SIMPULAN}

Yayasan Pendidikan Islam Daarurrahmah (YAPIDA) ini termasuk sekolah yang jumlah siswanya tiap tahun meningkat dilihat dari tahun-tahun sebelumnya, hal ini menyebabkan kepala sekolah tidak dapat mengelola semuanya dengan baik dan merasa kerepotan menangani hal tersebut. Dikarenakan proses pendataan yang masih manual, sehingga dirasa kurang optimal dan memerlukan yang cukup lama baik dalam menyusun laporan. Untuk menyelesaikan persoalan ini maka perlu untuk merancang sebuah aplikasi untuk membantu kepala sekolah dalam mendata akademik sekolah. Menambahkan pemberitahuan baik dengan sistem akademik pada deksktop atau pemberitahuan dengan sistem tampilan display layar monitor. Sehingga ketika bagian kurikulum mengkonfirmasikan data, akan secara terstruktur.Bagian Kurikulum akan mudah mencari data secara cepat berikut dengan lampiran laporan data yang akan dilaporkan setiap bulannya.

\section{DAFTAR PUSTAKA}

Dhanta.(2015). Aplikasi Berbasis Web. Aplikasi Berbasis Web.

Krismaji. (2015). Pengertian sistem menurut krismaji. In Sistem Informasi Akuntansi.

Mulyanto, A. (2009). Sistem Informasi Konsep dan Aplikasi. Yogyakarta: Pustaka Pelajar. https://doi.org/10.1007/s13398-014-0173-7.2

Satzinger, J. W., Jackson, R. B., \& Burd, S. D. (2012). Approaches to System Development. In Systems Analysis and Design in a Changing World.

Susanti, M. (2016). Perancangan Sistem Informasi Akademik Berbasis Web Pada Smk Pasar Minggu Jakarta: Informatika.

Sutabri, T. (2012). Analisis Sistem Informasi. In Analisa Sistem Informasi. 